\title{
Sow removal patterns in commercial breed-wean herds of Midwest, USA
}

\author{
${ }^{1}$ Joab Malanda $-{ }^{2}$ Péter Balogh $-{ }^{1}$ Gabriella Novotni Dankó \\ ${ }^{1}$ University of Debrecen, Faculty of Agricultural and Food sciences and Environmental Management, \\ Department of Animal Husbandry, Hungary \\ ${ }^{2}$ University of Debrecen, Faculty of Economics and Businesses, Institute of Sectoral Economics and Methodology, Hungary \\ mtolivet.livet@gmail.com
}

\begin{abstract}
SUMMARY
An observational retrospective study was done to provide up-to-date information on recent sow removal patterns from 9 breed-wean herds of Midwest USA. The study comprised of sow's removal reasons and removal types of F1 Landrace x Yorkshire gilts entered in the herds between $1^{\text {st }}$ Jan 2014 and $31^{\text {st }}$ July 2016. Data was extracted from existing database on Dec 2018 and 15\% of the sows were still active in the herds hence not included in the study. Descriptive statistics showed that out of the 20,009 removed sows, planned removals comprised of farrowing productivity (FP) 3,523 (17.6\%) and old age (OA) 1,785 (8.9\%) while unplanned removals consisted of reproductive failure (RF) 7,786 (38.9\%), health problems (HP) 2,629 (13.1\%), locomotion problems (LP) 1,473 (7.4\%) and conformation issues (CI) 1,350 (6.8\%). 'Did not conceive' and "No heat" were observed as the main contributing factors accounting for 37.6\% and 32.9\% respectively for gilts \& sows removed by RF.13.5\% of the gilts (Parity 0) were removed from the herds before attaining their first litter of which $64.1 \%$ of their removals was due to RF. Removal type consisted of slaughter (S) 85.0\%, found dead on the farm (DoF) 10.8\% and euthanized (E) $4.2 \%$. The research findings depict an upward trend of sow RF removals in the US swine herds posing a serious concern for US swine producers. Characterization and quantification of sow removals gives a revelation on the deeper intrigues about the vulnerability of the various parity in respect to common causes of RF. This helps swine producers to decisively improve on gilt replacement selection, reproductive efficiency, health and nutrition management all aimed at increasing overall swine productivity and efficiency in management. Swine farmers in the US can now focus their efforts towards curbing unnecessary $R F$ removal within parity specifics.
\end{abstract}

Keywords: sow, remove reason, remove type, commercial herds, United States

\section{INTRODUCTION}

Sow removal comprises of culling and mortality. The reasons for culling in a commercial sow herds have been well documented, and various studies have found out that major reasons are associated with reproductive problems, lameness as well as low levels of productivity Mote et al. (2009) and Segura-Correa et al. (2011). Two kinds of sow removal exist comprising of planned removal of old sows as a natural component in swine production and removal of low productive sows. Unplanned removal includes removal of sows due to reasons such as reproductive failure, lameness and mortality. Unplanned removals however depend on management practices since management decisions govern the implementation of sound culling policies which in turn give more control to swine producers over which sows can stay in the herd and which ones should be culled (Sasaki and Koketsu, 2012). Uninformed decision would result in undesirable sow removals which becomes economical to the producer. Current knowledge about characterization and quantification of sow removal pattern among US commercial piglet producing herds is not up to date. A recent US retrospective study by Mote et al. (2009) showed that $35.1 \%$ of the sows are removed by reproduction issues. Though this study brings out ideal findings which are scientifically beneficial, however it is 10 years old, based on a sample population of 2,000 sows and did not capture the aspect of removal type which is appropriate to be studied alongside removal reason. There has been an immense improvement in swine operations in the United States coupled with improved and efficient swine genetics, restructuring of housing system to cope up with the adverse changing climate, and an increased swine population (www.nationalhogfarmer.com). It is therefore of interest to categorize and quantify the sow removal reasons and types among US sows of today. Emphasis will be focused on the Midwest United States also called the Corn Belt area having large population of swine herds in the United States (www.nationalhogfarmer.com). Current findings will help identify problems facing the US swine industry and offer insights into overcoming undesirable RF removals in the current swine industry.

\section{MATERIALS AND METHODS}

Animal Welfare and Ethics Committee approval was not obtained for this study because the data used for this analysis was obtained from a private company's existing Porcitec database.

Data consisted of F1 Landrace $\mathrm{x}$ Yorkshire gilts entered in the herds from $1^{\text {st }}$ Jan 2014 until $31^{\text {st }}$ July 2016. At the time of data extraction Dec 2018, $15 \%$ of the gilts entered were still active in the herds and were not included in the study. The selected breed -wean farms are located in the Midwest of the United States. Swine production in these states can be visualized as a pyramid consisting of four levels (top-down): nucleus herds, multiplier herds, piglet producing herds, and fattening herds (Simonsson and Rydhmer, 1996). Gilts were purchased from multiplier herds within the US and Canada and transported to the selected farms for gilt development. The F1 Landrace $\mathrm{x}$ Yorkshire gilts in the selected herds were managed under similar 
management operations in all the farms hence no herd effect was put in consideration during our analysis. To be included in the present study, herds had to be free from incidences of Porcine Reproductive and Respiratory Syndrome (PPRS) and Porcine Epidemic Diarrhea (PED) which have been found to be the most economical diseases affecting swine industry in the US Holtkamp et al. (2013). The herds were also selected on their merit of completeness and accuracy of recording data. The following information was extracted from the database; sow tag number, removal reason, removal type and parity at removal. Gilts, designated as parity $0(\mathrm{P} 0)$, were included in the analysis and sows greater than parity $6(\mathrm{P} 6)$ were excluded from the study since the private company's policy stipulates culling of $>\mathrm{P} 6$ sows. All sows with missing values in the dataset were excluded and the final data set containing 20,009 individual sows and records was exported as excel-file into IBM SPSS Statistics version 25 (IBM SPSS Inc, Armonk NY.,USA) where all descriptive statistics were obtained.

The study used the model of $\mathrm{TPB}_{\mathrm{ijklmno}}=\mu+\mathrm{ORIG}_{\mathrm{i}}+\mathrm{GEN}_{\mathrm{j}}+\mathrm{ReR}_{\mathrm{k}}+\mathrm{S} 1 \mathrm{AGE}_{\mathrm{l}}+$ $\mathrm{LFR}_{\mathrm{m}}+\mathrm{RA}_{\mathrm{n}}+\mathrm{GEN}_{\mathrm{j}} * \mathrm{ReR}_{\mathrm{k}}+\varepsilon_{\mathrm{ijk} l m n o}$ where: TPB $_{\text {ijklmno }}$ - Total Pigs Born (TPB) as a dependent variable; $\mu$ - overall mean; $\mathrm{ORIG}_{\mathrm{i}}-$ Country of origin (USA or Canada) as a main effect; $\mathrm{GEN}_{\mathrm{j}}-$ Genetics $(1,2)$ as a main effect; $\operatorname{ReR}_{\mathrm{k}}$ - Removal reason as a main effect; $\mathrm{S}_{\mathrm{AGE}}$ - Serving 1 Age as a covariance; $\mathrm{LFR}_{\mathrm{m}}$ - Lifetime farrowing rate as a covariance; $\mathrm{RA}_{\mathrm{k}}$ - Removal Age (RA) as a covariance; $\mathrm{GEN}_{\mathrm{j}} * \mathrm{ReR}_{\mathrm{k}}$ - interaction effect; $\varepsilon_{\mathrm{ijklmno}}-$ Random Error.

\section{RESULTS}

The research identified 31 causes of sow removal reasons and classified them into 7 main groups of 2 categories (Table 1). Largest contribution to removal was made by RF followed by FP, HP, OA, LP and CI. "Other " $(\mathrm{O})$ was also included in the study as an amalgamation of removal reasons that couldn't be grouped individually due to their fewer entries (Table 1).

Additionally, 3 remove types were identified, slaughter was the most common removal type followed by death on farm and euthanized sows (Table 2).

Reasons of sow culling and its frequency (\%) in Midwest herds of US

\begin{tabular}{|c|c|c|c|c|}
\hline Removal type & Removal reason & $\mathrm{N}$ & Freq $(\%)$ & consist of \\
\hline \multirow[t]{2}{*}{ Planned } & Old age $(\mathrm{OA})$ & 1,785 & 8.9 & old age \\
\hline & Farrowing productivity (FP) & 3,523 & 17.6 & $\begin{array}{l}\text { lack of farrowing productivity, } \\
\text { lactation to weaning productivity, }\end{array}$ \\
\hline \multirow[t]{5}{*}{ Unplanned } & Reproductive failure (RF) & 7,786 & 38.9 & $\begin{array}{l}\text { no heat, did not conceive, fail to farrow, } \\
\text { difficult farrowing, abortion }\end{array}$ \\
\hline & Health problems (HP) & 2,629 & 13.1 & $\begin{array}{l}\text { acute heart failure, hemorrhagic bowel, ileitis, pneumonia, } \\
\text { puffer sow, ulcer, strep, twisted gut, vaginal discharge, } \\
\text { vaginal prolapse, rectal prolapse }\end{array}$ \\
\hline & Conformation issues $(\mathrm{CI})$ & 1,350 & 6.8 & body condition score, poor udderline \\
\hline & Locomotion problems (LP) & 1,473 & 7.4 & lameness, leg injury, downer sow, \\
\hline & Other $(\mathrm{O})$ & 1,463 & 7.3 & $\begin{array}{l}\text { behavior problem, management, adjust, off feed, } \\
\text { research, found dead, unknown }\end{array}$ \\
\hline Total & & 20,009 & $100 \%$ & \\
\hline
\end{tabular}

Table 2 Overall sow removal types and its frequency $(\%)$ in Midwest herds of US

\begin{tabular}{lccc}
\hline \multicolumn{1}{c}{ Remove type } & Abbreviation & $\mathrm{n}$ & proportion\% \\
\hline Death on farm & (DoF) & 2,168 & $10.8 \%$ \\
Slaughter & $(\mathrm{S})$ & 17,008 & $85.0 \%$ \\
Euthanized & $(\mathrm{E})$ & 833 & $4.2 \%$ \\
\hline Total & & 20,009 & $100 \%$ \\
\hline
\end{tabular}

The results show a progressive increase in frequency of removal by old age which is viewed as an expected trend. Farrowing productivity, health problems and conformation issues have unbalanced trend of removal in the results however there is a notable decreasing trend of removal by reproductive failure across parities except a slight increase in Parity 3 (Figure 1).
Figure 1: Distribution of reproductive failure according to parity in the study

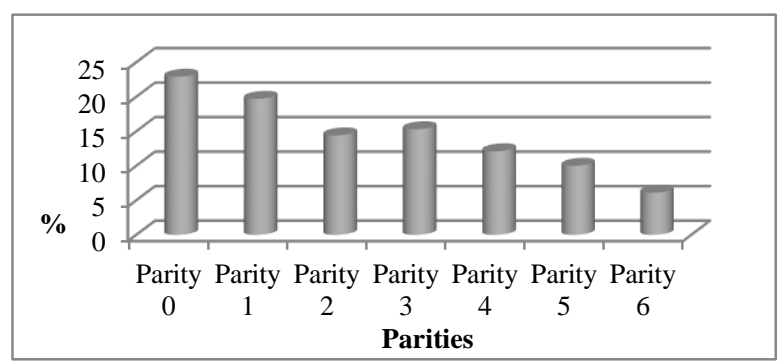

The overall proportion of reproductive failure causes was determined using IBM SPSS version 25 descriptive (Table 3). 
Table 3

Overall Reproductive failure causes and their proportion in the study

\begin{tabular}{lcc}
\hline Reproductive failure cause & $\mathrm{n}$ & proportion $\%$ \\
\hline Abortion & 866 & $11.2 \%$ \\
Did not conceive & 2,929 & $37.6 \%$ \\
No heat & 2,568 & $32.9 \%$ \\
Fail to farrow & 942 & $12.1 \%$ \\
Difficult farrowing & 481 & $6.2 \%$ \\
\hline Total & 7,786 & $100 \%$ \\
\hline
\end{tabular}

Furthermore an inside examination of how parities are vulnerability to various causes of reproductive failure was determined (Figure 2).

Additionally there is a notable decreasing trend of removal by locomotion problems as sows grow older (see Table 4). Reproductive failure was the most important unplanned reason for removal in all parities accounting for $38.6 \%$ of the total removals (Table 2). 'Did not conceive' and "No heat" were observed as the main contributing factors accounting for $37.6 \%$ and $32.9 \%$ respectively for sows removed by reproductive failure (Table 3).

Figure 2: Trend of Reproductive failure causes within parities

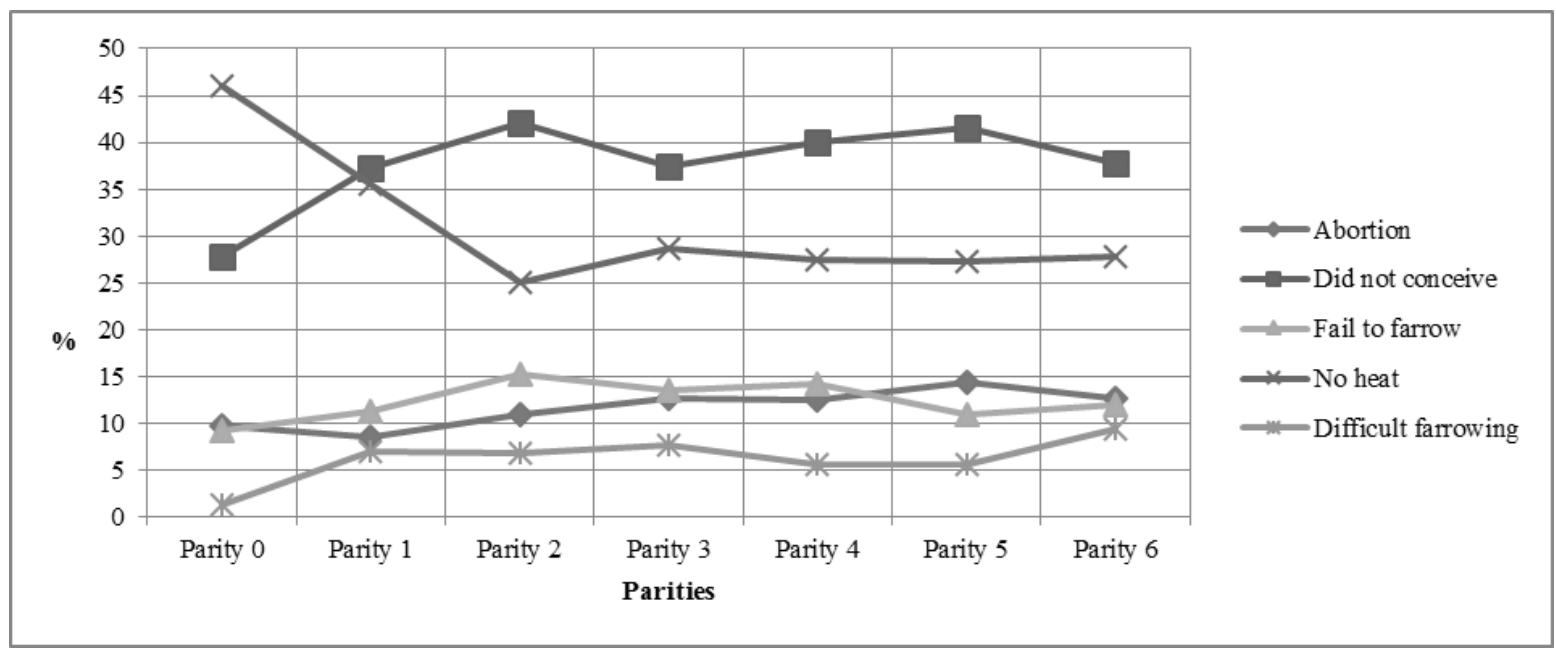

Remove reasons distribution according to parity at removal

\begin{tabular}{|c|c|c|c|c|c|c|c|c|c|}
\hline \multirow{2}{*}{ Remove reason } & $\mathrm{OA}$ & FP & $\mathrm{RF}$ & $\mathrm{HP}$ & CI & LP & $\mathrm{O}$ & Total & \multirow{2}{*}{$\%$} \\
\hline & $\mathrm{n}$ & $\mathrm{n}$ & $\mathrm{n}$ & $\mathrm{n}$ & $\mathrm{n}$ & $\mathrm{n}$ & $\mathrm{n}$ & $\mathrm{n}$ & \\
\hline Parity 0 & 0 & 8 & 1734 & 362 & 89 & 320 & 191 & 2704 & $13.5 \%$ \\
\hline Parity 1 & 0 & 514 & 1537 & 432 & 231 & 341 & 295 & 3350 & $16.8 \%$ \\
\hline Parity 2 & 0 & 393 & 1125 & 410 & 194 & 207 & 238 & 2567 & $12.8 \%$ \\
\hline Parity 3 & 0 & 538 & 1195 & 420 & 201 & 188 & 214 & 2756 & $13.8 \%$ \\
\hline Parity 4 & 202 & 697 & 940 & 383 & 283 & 174 & 209 & 2888 & $14.4 \%$ \\
\hline Parity 5 & 646 & 656 & 782 & 353 & 205 & 140 & 160 & 2942 & $14.7 \%$ \\
\hline Parity 6 & 937 & 717 & 473 & 269 & 147 & 103 & 156 & 2802 & $14.0 \%$ \\
\hline Total & 1,785 & 3,523 & 7,786 & 2,629 & 1,350 & 1,473 & 1,463 & $=20,009$ & $(100 \%)$ \\
\hline
\end{tabular}

Parity0 were most vulnerable for removal by reproductive failure accounting for $64.1 \%$ of their total removal. Parity 6 had a lesser chance of being removed due to reproductive failure but had a higher chance of removal due to FP (see Table 4). Slaughter was the most convenient type of removal amongst all the sows accounting for $85.0 \%$ of the sows removed. Mortality on farm comprising of found dead and euthanized accounted for $10.2 \%$ and $4.2 \%$ respectively (Table 2). Reproductive failure is seen as the most economical removal reason in sow farms and this study goes further to illustrate the current trend of reproductive failure removal in the US swine farms and how the risk of RF is distributed across Parity0 to parity6.

\section{DISCUSSION}

A limitation should be considered when interpreting the results of this study. The study was not a controlled experiment, but a retrospective observation of stored farm data from a private sow company's database. This study focused on commercial swine farms in the Midwest of United States who practice breed to wean systems of swine production using F1 Landrace and Yorkshire gilts and observing similar management 
operations across all the selected herds. However, even with such limitations, farm data analysis using appropriate exclusion criteria can disseminate practical and readily applicable information to swine producers about production issues that are difficult to investigate under controlled experiments and hence this research provides up to date valuable information about the characterization and quantification of sow removal reasons and types under commercial production in the United States.

Information regarding reasons for sow removal is important in swine operations since it's linked to a better understanding of underlying issues such as disease and management problems in swine herds Balogh et al. (2015). Overall, management and production system has been reported to influence the removal pattern of sows Morris et al. (1998) and Akos and Bilkei (2004), however, it is the herdsman's subjective decision that determines whether a sow is removed or not since he puts into consideration aspects such as sow's parity number, production, reproductive status, health status and herd structure, as well as access to replacement gilts of relevant reproductive status.

The findings in this study establishes a higher percentage of sows being removed in the early parities $(<\mathrm{P} 3)$ representing a third of the total sow removals. This findings are in agreement with previous studies done globally by, D'Allaire et al. (1987), Patterson et al. (1996), Rodriguez-Zas et al. (2003), Engblom et al. (2007), Hoge and Bates (2011) and Masaka et al. (2014). Sow removal continues to receive more attention due to its economic and ethical importance since a high removal rate is associated with poor longevity. Removal of younger parities from the herds affects the herd age structure and prevents most of them from reaching peak performance. Removal of sows is obviously based on several contributing causes, though there are 2 major kinds of removal. Planned removal comprising of the natural removal of old sows and low productive sows. In this study old sows were mainly removed because of the subjective removal reason of old age, which accounted for $8.9 \%$ (see Table 1).This findings are in consistent with US study by Lucia et al. (2000), who reported $8.7 \%$ of the sows being removed by OA. Since, increase in chronological sow age is directly proportional to increase in parity, in this study the percentage of sows removed due to old age also have a high chance of being removed due to farrowing productivity indicating decreased performance with increase in age, a similar finding made by de Jong et al. (2014).

Farrowing productivity category included sows that were culled for lack of farrowing productivity or lactation-weaning productivity. Farrowing productivity is termed as planned removal since a sow that fails to achieve a certain productive potential is eliminated from the herd. In this study $17.6 \%$ (see Table 1) lower than $20.6 \%$ that was reported by Lucia et al. (2000) of the sows were removed due to farrowing productivity implying that this sows failed to meet the producer requirements for them to be sustained in the herd but also it could explain that modern sows are more efficient than sows of 19 years ago. Though voluntary culling of repeated low-performing sows has obvious benefits to the operation, but it should be noted that removal of low performing sows in early parities is uneconomical. According to Stalder et al. (2003) at least three litters are required from a sow before it gives a positive cash flow for the producer while other studies have estimated the optimal economic lifespan being at least five parities (Scholman and Dijkhuizen, 1989). Although sows that remain in the herd for multiple parities have more opportunity to be sufficiently productive to offset the initial replacement cost and gilt development costs associated with each sow (Stalder, 2003), however it should be noted that one of the limitation in this study was that the company's policy where data was extracted stipulated a culling parity of >P6 hence all the sows analyzed were until P6 removal.

Unplanned removal include removal of sows due to reasons such as reproductive failure, locomotory issues, health problems, conformation issues and mortality. This kind of removal is termed as functional longevity which is focused on removal of an animal with reason unrelated to production i.e. culling of an animal at a time and for a reason not chosen by the farmer Ducrocq et al. (1988). In this research, (see Table 1) the most commonly reported reason for unplanned removals was reproductive failure accounting for $38.9 \%$ of all removals, followed by health problems $13.1 \%$, locomotion problems $7.4 \%$ and conformation issues $6.8 \%$. Similar findings have been reported in studies done by Sehested and Schjerve (1996), Boyle et al. (1998) and Balogh et al. (2015). However studies done by Christensen et al. (1995), and Sanz et al. (2007) found locomotory issues as the most common remove reason for the unplanned cases. There is an emerging trend of reproductive failure removal of sows in the US (Table 5). This gradual increase in the percentage of sows removed by reproductive failure should pose a serious concern.

Table 5

Reproductive failure in US studies, reported findings

\begin{tabular}{lcc}
\hline $\begin{array}{c}\text { Reference studies done in } \\
\text { the US }\end{array}$ & $\begin{array}{c}\text { no of sows } \\
\text { used }\end{array}$ & RF proportion\% \\
\hline D'Allaire et al., (1987) & 7,242 & $32.0 \%$ \\
Stein et al., (1990) & 774 & $29.6 \%$ \\
Lucia et al., (2000) & 7,973 & $33.6 \%$ \\
Mote et al., (2009) & 2,000 & $35.1 \%$ \\
\hline
\end{tabular}

This research study (2019) $\mathrm{n}=20,009$ findings portray an upward trend RF $(38.9 \%)$ which should be of concern to swine producers in the US.

Figure 2 shows, Gilts (P0) are highly vulnerable to experiencing no heat as a major indicator of their reproductive failure. This could be attributed to various management practices such as limited boar exposure of pre-pubertal gilts in the Gilt Development Units (GDU), silent heat gilts could go unnoticed during heat checking.

The trend of "no heat "slows down and stabilizes as parity increases, this could be attributed to the fact that 
many gilts that survive the removal by "no heat" end up gaining synchrony with the association of the higher parities in the herds as their risk of removal is higher in the GDU. On the contrary Gilts (P0) experience a lesser risk of removal due to not conceiving which could be associated with their newness in reproductive life and being viewed as "fresh" animals. The risk of removal by not conceiving gains an upward trend as age increases. This can be explained by the fact that as the sow grows older the vitality and purity of the reproductive tract slows down from the past experiences of pregnancies. Though RF occurs in all swine farms globally, and its significant should only be regarded when it falls below the expected norm, however modern swine production is highly focused on efficiency and costs. Gilts/sows that fail to come in heat/conceive are viewed as uneconomical to be sustained in the herds and due to this strictness aimed at avoiding buildup of nonproductive days most gilts/sows rarely get a second chance. Principally this could explain why there is a high number of removals by "did not conceive" and "no heat" being experienced in young parities. The high number of removals in young parities affects their overall herd performance as reported by Dagorn and Aumaitre (1979), Dijkhuizen et al. (1989) and Niemi et al. (2017). In this study, removal by difficult farrowing, fail to farrow and abortion portrays a lower risk among all the parities in modern swine operations. Even though this lower risk cannot be attributed to a single factor but combined effort of various management, veterinary intervention and the fact that modern sow genotypes are being breed for efficiency could be the reason. The small percentage of P0 removed by difficult farrowing could be attributed to the fact that, naturally farrowing for the first time is a hefty challenge for the gilts, termed as physiologically, physically and emotionally very stressful. Because of this associated stress unlucky gilts end up by not having their first piglet during farrowing which leads to their early elimination from the herd. However Hughes (1998) established that litter size increases from $\mathrm{P} 1-\mathrm{P} 4$, modern sow genotypes are breed to farrow many piglets. The number and size of the piglets could affect the sow farrowing ease, though in this specific study it appears that difficult farrowing has the least threat with a range of 5-10\% across parities.

Removal of sows includes sows that are not sent to slaughter, but are found dead or euthanized on farm. Mortality can make up a significant portion of the total sows removed from a breeding herd, also sows euthanized on farm due to trauma or disease are generally included in studies on mortality. Mortality rate as a percentage of sows in this study is reported at $10.8 \%$ which is in agreement with US studies contacted by D'Allaire et al. (1987) and Lucia et al. (2000) who reported $11.6 \%$ and $7.4 \%$ respectively.

\section{CONCLUSION}

Unplanned removal by RF is inevitable, however as shown in this research the most RF causes "did not conceive" and "no heat" involve management practices. Management of RF can only be satisfactory if swine producers approach it through a cause and parity specific unlike a wholesome approach. Since RF removals are highest in gilts (P0), measures should be taken for appropriate gilt selection and initiation in the herd. There is need for adequate and timely boar exposure to prepubertal gilts as a way of stimulating them to come in first heat but also multiparous sows after weaning to stimulate them back to cycle. Efficient and steady heat check should be enhanced to spot gilts/ sows that could be experiencing silent heats. A combined success of good quality semen, physical and physiological receptive gilt/sow at insemination and the keenness of the inseminator results to positive conception. Essentially, timely insemination of gilts/weaned sows that proved sufficient "lock-up" /standing heat at the time of heat check should be emphasized to reduce the increased incidences of conception failure. Overall sound management planning and execution of informed decision should be adhered to avoid unnecessary sow removals that are becoming very economical. This will therefore contribute to cumulative objective of improved swine productivity and efficiency.

\section{Conflict of interest}

The authors declare no conflict of interest. The research was conducted in the absence of any commercial or financial relationships that could be construed as a potential conflict of interest.

\section{Availability of data and materials}

This work was part of the Master's thesis research. The data sets in this study are not publicly available due to protection of privacy and farm details. The private company provided data only to be used in the master's research thesis at University of Debrecen, Hungary by a particular research group.

\section{REFERENCES}

Akos, K.-Bilkei, G. (2004): Comparison of the reproductive performance of sows kept outdoors in Croatia with that of sows kept indoors. Livestock Production Science 85, 293-298.

Balogh, P.-Kapelan'ski, W.-Jankowiak, H.-Nagy, L.-Kovács, S.Huzsvai, L.-Popp, J.-Posta, J.-Soltész, A. (2015): The productive lifetime of sows on two farms from the aspect of reasons for culling. Ann. Anim. Sci. 15, 747-758.

Boyle, L.-Leonard, F.C.-Lynch, B.-Brophy, P. (1998): Sow culling patterns and sow welfare. Irish Veterinary Journal 51, 354-357. 
Christensen, G.-Vraa-Andersen, L.-Mousing, J. (1995): Causes of mortality among sows in Danish pig herds. Veterinary Record 137, 395-399.

Dagorn, J.-Aumaitre, A. (1979): Sow culling: Reasons for and effect on productivity. Livestock Production Science Volume 6, Issue 2, Pages 167-177.

D'Allaire, S.-Stein, T. E.-Leman, A. D. (1987): Culling patterns in selected Minnesota swine breeding herds. Can. J. Vet. Res. 51, 506-512.

De Jong, E.-Appeltant, R.-Cools, A.-Beek, J.-Boyen, F.-Chiers, K.-Maes, D. (2014): Slaughterhouse examination of culled sows in commercial pig herds. Livest. Sci., 167: 362-369.

Dijkhuizen, A.-Krabbenborg, M.-Huirne, M. (1989): Sow replacement: A comparison of farmers' actual decisions and model recommendations. Livestock Production Science Volume 23, Issues 1-2, 207-218.

Ducrocq, V.-Quaas, R. L.-Pollak, E. J.-Casella, G. (1988): Length of productive life of dairy cows. Journal of Dairy Science 71, 3061-3070.

Engblom, L.-Lundeheim, N.-Anne-Marie, D.-Andersson, K (2007): Sow removal in Swedish commercial herds. Livestock Science Volume 106, Issue 1, January 2007, 76-86.

Hoge, M. D.-Bates, R. O. (2011): Developmental factors that influence sow longevity. Journal of Animal Science.89:12381245.

Holtkamp, D. J.-Kliebenstein, J. B.-Neumann, E. J.-Zimmerman, J. J.-Rotto, H. F.-Yoder, T. K.-Wang, C.-Yeske, P. E.-Mowrer, C. L.-Haley, C. A. (2013): Assessment of the economic impact of porcine reproductive and respiratory syndrome virus on United States pork producers. J Swine Health Prod.21:72-84.

Hughes, P. E. (1998): Effects of parity, season and boar contact on the reproductive performance of weaned sows. Livestock Production Science; 54:151-157.

Lucia, T. Jr.-Dial, G. D.-Marsh, W. E. (2000): Lifetime reproductive performance in female pigs having distinct reasons for removal. Livest. Prod. Sci. 63, 213-222.

Masaka, L.-Sungirai, M.-Nyamukanza, C. (2014): Sow removal in a commercial pig herd in Zimbabwe. Trop Anim Health Prod 46 725-731.

Morris, J. R.-Hurnik, J. F.-Friendship, R. M.-Evans, N. M. (1998): The effect of the Hurnik-Morris (HM) system on sow reproduction, attrition, and longevity. Journal of Animal Science $76,2759-2762$.

Mote, B. E.-Mabry, J. W.-Stalder, K. J.-Rothschild, M. F. (2009) Evaluation of current reasons for removal of sows from commercial farms, The Professional Animal Scientist, 25, 1-7.
Niemi, J.-Bergman, P.-Ovaska, S.-Sevón-Aimonen, L.-Heinonen, M. (2017): Modeling the costs of postpartum dysgalactia syndrome and locomotory disorders on sow productivity and replacement. Front. Vet. Sci., 4, page 181.

Patterson, R. A.-Cargill, C. F.-Poiton, A. M. (1996): Investigating sow deaths and excessive culling in Australian pig herds. In: Proceedings of the 14th International Pig Veterinary Society Congress, Bologna, Italy, p. 493.

Rodriguez-Zas, S. L.-Southey, B. R.-Knox, R. V.-Connor, J. F.Lowe, B. J.-Roskamp (2003): Bioeconomic evaluation of sow longevity and profitability. Journal of Animal Science, Volume 81, Issue 12, 2915-2922.

Sasaki, Y.-Koketsu, Y. (2012): A herd management survey on culling guidelines and actual culling practices in three herd groups based on reproductive productivity in Japanese commercial swine herds, Journal of Animal Science, 90, 19952002.

Sanz, M.-Roberts, J. D.-Perfumo, C. J.-Alvarez, R. M.-Donovan, T.-Almond, G. W. (2007): Assessment of sow mortality in a large herd. Journal of Swine Health and Production 15, 30-36.

Scholman, G. J.-Dijkhuizen, A. A. (1989): Determination and analysis of the economic optimum culling strategy in swine breeding herds in Western Europe and the USA. Netherlands Journal of Agricultural Science 37, 71-74.

Segura-Correa, J. C.-Ek-Mex, E.-Alzina-López, A.-Segura-Correa, V. M. (2011): Frequency of removal reasons of sows in Southeastern Mexico, Tropical Animal Health and Production, 43, 1583-1588.

Sehested, E.-Schjerve, A. (1996): Aspects of sow longevity based on analyses of Norwegian sow recording data. In: Proceedings of Nordiska Jordbruksforskares Förening, Seminar no. 265, Research Centre Foulum, Denmark, vol 111, 9-16.

Simonsson, A.-Rydhmer, L. (1996): Pig production in Sweden. Pig News and Information $17,25 \mathrm{~N}-27 \mathrm{~N}$.

Stalder, K. J.-Lacy, R. C.-Cross, T. L.-Conatser, G. E. (2003): Financial impact of average parity of culled females in a breedto-wean swine operation using replacement gilt net present value analysis. Journal of Swine Health and Production 11, 69-74.

Stein, T. E. A.-Dijkhuizen, S.-D'Allaire, R.S. -Morris (1990): Sow culling and mortality in commercial swine breeding herds. Preventive Veterinary Medicine, 9 85-94.

www.nationalhogfarmer.com 